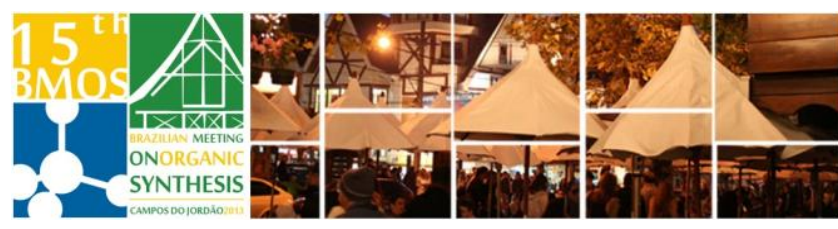

\title{
$\beta$-C-ribosyl-1,2,3-triazole analogues of guanosine as potencial antiviral agents against dengue and hepatitis $C$ virus
}

Alexandra Basilio Lopes $^{\S}$, Nelilma Correia Romeirow, Amilcar Tanuri ${ }^{*}$, Nadège LubinGermain $^{\dagger}$, Rodrigo Octávio M. A. de Souza ${ }^{s}$, Leandro S.M. Miranda ${ }^{\varsigma}$

${ }^{\mathfrak{s}}$ Federal University of Rio de Janeiro, BOSS Laboratory, ${ }^{\dagger}$ University of Cergy-Pontoise, SOSCO Laboratory, EA 4505, ${ }^{7}$ Federal University of Rio de Janeiro, Molecular Virology Laboratory, ${ }^{\psi}$ Federal University of Rio de Janeiro-Campus Macaé Professor Aloísio Teixeira, LICC-Laboratório Integrado de Computação Científica

\section{*alexandralopesb@yahoo.com.br}

Keywords: HCV, Dengue, C-nucleosides

\section{INTRODUCTION}

Dengue and hepatitis $\mathrm{C}$ virus $(\mathrm{HCV})$ are positive sense RNA viruses belonging to the genus Flavivirus. HCV is a leading cause of liver failure and hepatocellular carcinoma and infects about $3 \%$ of the population worldwide. Dengue is an acute infection caused by any of four serotypes (DENV1-4) and approximately 390 million cases occur each year around the globe. Despite of efforts, there are neither effective vaccines nor specific antiviral treatment for DENV1-4, and the therapies available to treat $\mathrm{HCV}$ based on pegylated interferon/ribavirin and protease inhibitors need to be improved, considering the side effects, tolerability, cost and sustained virologic response (SVR). Recently C nucleosides were reported to be highly active against $\mathrm{HCV}$, inhibiting non-structural NS5B protein of $\mathrm{HCV}$. Here, we report the synthesis of the key intermediate in the production of the designed $\beta-C$ ribosyl-1,2,3-triazole compounds structurally close to guanosine, as depicted below.
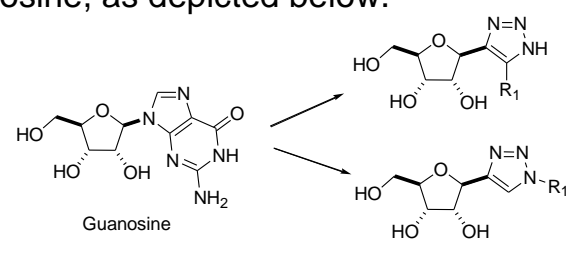

$\mathrm{R}_{1}=\mathrm{CO}_{2} \mathrm{Et}, \mathrm{CONH}_{2} \mathrm{CH}_{2} \mathrm{NH}_{2}$

$\mathrm{COOH}, \mathrm{CONHNH} \mathrm{H}_{2} \mathrm{CONH}-\left(=\mathrm{NH}_{2}\right)-\mathrm{NH}$

\section{RESULTS AND DISCUSSION}

The strategy for the synthesis of the designed Ribosyl-C-Nucleosides was pursuit though the approach developed by Lubin and col. ${ }^{1}$ which involved the synthesis of the corresponding ribosyl acetylene though an Indium mediated alkynylation reaction. For such, the synthesis of the appropriate Ribosyl donor for the alkynylation was achieved as depicted in Figure 1. Two steps involving common protections of D-ribose (1) furnished compound 2. The diacetate (2) was engaged with ethyl 3-iodopropiolate in an indium-mediated alkynylation reaction. In the present case this reaction presented complete $\beta$-selectivity. However, as described, such alkynylation reaction was investigated in an attempt to reduce such drawbacks. The replacement of DCM to DCE allowed us to reduce the reaction time by increasing the temperature. The best result was achieved at $90^{\circ} \mathrm{C}$.

Table 1. Studies related to Alkynylation step

\begin{tabular}{|c|c|c|c|}
\hline Solvent & Temp $\left({ }^{\circ} \mathrm{C}\right)$ & Time $(\mathrm{h})$ & Yield $(\%)$ \\
\hline DCM & 50 & 72 & $30^{*}$ \\
DCE & 75 & 16 & 47 \\
DCE & 90 & 4 & 46 \\
DCE & 110 & 4 & 37 \\
\hline
\end{tabular}

"made as described by Youcef, R. A. et al

Further, acetylene $\mathbf{3}$ was reacted in Huisgen cycloaddition with benzylazide. The regiosselectivity of this transformation was inconsequential since both regioisomers converged to the same 4,5dissubstituted triazole 4, after quantitative debenzylation, in the presence of ammonium formate and $\mathrm{Pd} / \mathrm{C}$.

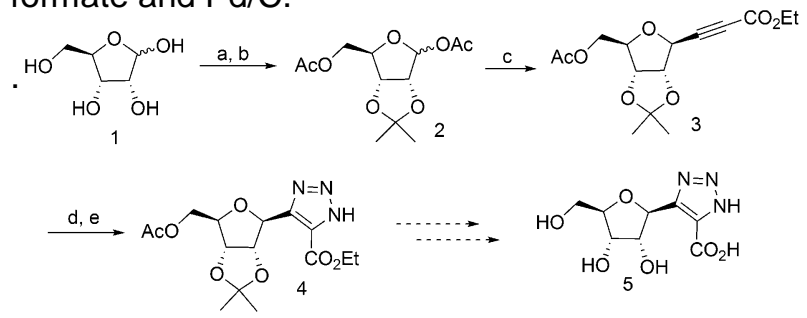

Reaction Conditions: a. acetone, DMP, TsOH, $0.5 \mathrm{~h}, \mathrm{rt}, 40-80 \%$; b. $\mathrm{Ac}_{2} \mathrm{O}, \mathrm{Py}, 80^{\circ} \mathrm{C}, 24 \mathrm{~h}$, $63 \%$; c. ethyl 3-iodo-propiolate (2equiv), In (1.6 equiv), DCE, $90^{\circ} \mathrm{C}, 4 \mathrm{~h}, 46 \%$; d. $\mathrm{BnN}_{3}$, toluene, $110^{\circ} \mathrm{C}, 24 \mathrm{~h}, 73 \%$; e. ammonium formate (5equiv), $\mathrm{Pd} / \mathrm{C} 10 \%(26 \mathrm{~mol} \%), \mathrm{MeOH}, 1 \mathrm{~h}$, $100 \%$

Figure 1. Synthesis of 4,5-disubstituted ribosyl-triazoles

\section{CONCLUSION}

The key intermediate 4 for the synthesis of the designed 4,5-disubstituted ribosyl-triazoles was synthetized in moderate overall yield, being the alkynylation the critical step. The synthesis of the desired guanosine analogues though functionalization of ethyl ester functionality of $\mathbf{4}$ are under investigation as well as the evaluation of their antiviral activity.

\section{ACKNOWLEDGEMENTS}

CNPq, FAPERJ, CAPES

\section{REFERENCES}

${ }^{1}$ Youcef, R. A. et al, J. Org. Chem. 2009, 74, 4318-4323. 